\title{
Space-Based Active Optical Remote Sensing of Carbon Dioxide Column USING High-ENERgy Two-Micron PULSED IPDA LIDAR
}

\section{Upendra N. Singh ${ }^{1 *}$, Tamer F. Refaat ${ }^{1}$, Syed Ismail ${ }^{2}$, Mulugeta Petros ${ }^{1}$, Kenneth J. Davis ${ }^{3}$, Stephan R. Kawa ${ }^{4}$, and Robert T. Menzies ${ }^{5}$}

\author{
${ }^{1}$ NASA Langley Research Center, Hampton,VA 23681, USA, *Email: Upendra.n.singh@nasa.gov \\ ${ }^{2}$ Analytical Services and Materials, Inc., Hampton, VA 23666, USA, \\ ${ }^{3}$ Pennsylvania State University, University Park, PA 16802, USA, \\ ${ }^{4}$ NASA Goddard Space Flight Center, Greenbelt, MD 20771, USA, \\ ${ }^{5}$ Jet Propulsion Laboratory, Pasadena, CA 91109, USA
}

\begin{abstract}
Modeling of a space-based high-energy 2- $\mu \mathrm{m}$ triple-pulse Integrated Path Differential Absorption (IPDA) lidar was conducted to demonstrate carbon dioxide $\left(\mathrm{CO}_{2}\right)$ measurement capability and to evaluate random and systematic errors. A high pulse energy laser and an advanced MCT e-APD detector were incorporated in this model. Projected performance shows $0.5 \mathrm{ppm}$ precision and $0.3 \mathrm{ppm}$ bias in low-tropospheric column $\mathrm{CO}_{2}$ mixing ratio measurements from space for 10 second signal averaging over Railroad Valley (RRV) reference surface.
\end{abstract}

\section{INTRODUCTION}

Sustained high-quality column $\mathrm{CO}_{2}$ measurements from space are required to improve estimates of regional and global scale sources and sinks to attribute them to specific biogeochemical processes for improving models of carbon-climate interactions and to reduce uncertainties in projecting future change. Critical regions for $\mathrm{CO}_{2}$ measurements are: high latitude ecosystems, tropical ecosystems, southern ocean, managed ecosystems, urban and industrial systems and coastal systems. The need for space-based IPDA measurements has been advocated by Active Sensing of CO2 Emission over Nights, Days, and Seasons (ASCENDS) [1] and Advanced Space Carbon and Climate Observation of Planet Earth (A-Scope) [2] studies. Space-based IPDA systems can provide sustained, high precision and low-bias column $\mathrm{CO}_{2}$ in presence of thin clouds and aerosols. Technology developments are in progress to provide high pulse energy $2-\mu \mathrm{m}$ IPDA that enables optimum, lower troposphere weighted column $\mathrm{CO}_{2}$ measurements from space. This system provides simultaneous ranging; information on aerosol and cloud distributions, measurements over region of broken clouds, and reduces influences of surface complexities. Modeling the performance of a direct-detection high pulse energy 2- $\mu \mathrm{m}$ IPDA from space is presented in this paper [3].

\section{MODEL BACKGROUND}

The IPDA lidar transmitter is based on highenergy, tunable, triple-pulse 2- $\mu \mathrm{m}$ laser under development at NASA LaRC. The IPDA lidar receiver is based on an advanced $\mathrm{HgCdTe}$ (MCT) electron avalanche photodiode (e-APD) detection system demonstrated at NASA GSFC. IPDA model for simulating $\mathrm{CO}_{2}$ Space-based measurements at $2-\mu \mathrm{m}$ was conducted assuming $400 \mathrm{~km}$ altitude dawn-dusk orbit platform with US Standard atmospheric model and RRV as a reference surface. Water vapor $\left(\mathrm{H}_{2} \mathrm{O}\right)$ is the dominant atmospheric molecule interfering $\mathrm{CO}_{2}$ measurements. Figure 1 shows $\mathrm{CO}_{2}$ (updated to $400 \mathrm{ppm}$ ) and $\mathrm{H}_{2} \mathrm{O}$ double-path

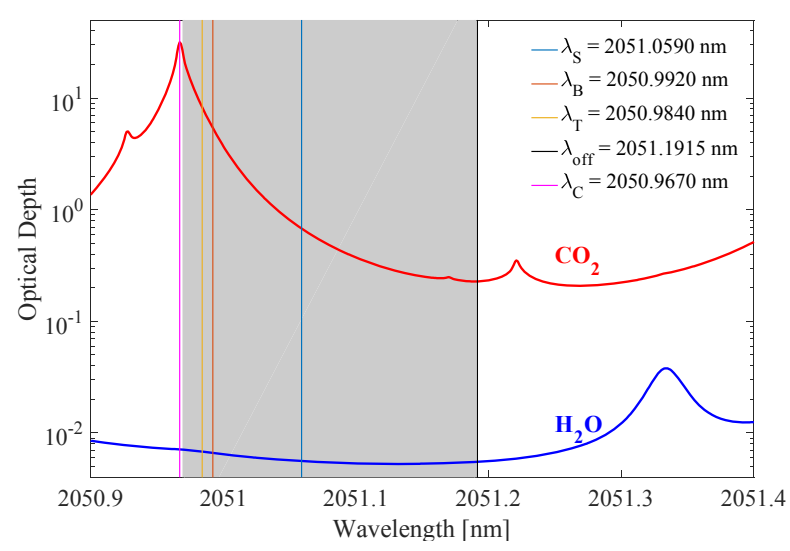

Figure 1 Integrated double-path differential optical depth spectra for $\mathrm{CO}_{2}$ and $\mathrm{H}_{2} \mathrm{O}$ obtained from $400 \mathrm{~km}$ altitude to mean sea level. Vertical lines mark selected on- and off-line wavelengths. 


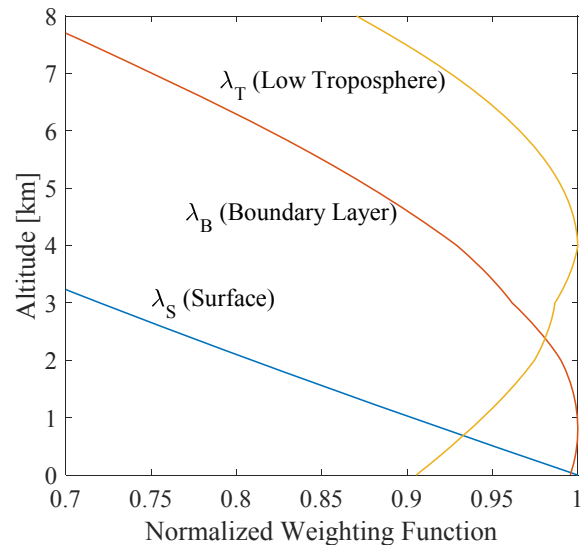

Figure 2 Pressure-based normalized weighting function for three selected on-line wavelengths, $\lambda_{S}, \lambda_{B}$ and $\lambda_{T}$ targeting surface, boundary layer and low tropospheric $\mathrm{CO}_{2}$ column measurement.

optical depth spectrum. Vertical lines mark on-line positions for near surface $\left(\lambda_{\mathrm{S}}\right)$, boundary layer $\left(\lambda_{\mathrm{B}}\right)$, and tropospheric $\left(\lambda_{\mathrm{T}}\right)$ weighted column $\mathrm{CO}_{2}$ measurements, as shown in figure 2, using common off-line wavelength $\left(\lambda_{\text {off }}\right)$. Figure 2 indicates that an IPDA operating at the $2-\mu \mathrm{m}$ wavelength region offers optimum $\mathrm{CO}_{2}$ measurements in the lower troposphere and improves retrieval of the critically important surface flux estimates by a factor of two compared with a similar IPDA operating at 1.6- $\mu \mathrm{m}$ [2].

\section{TECHNOLOGY DEVELOPMENTS}

Progress in laser and detector technologies and airborne testing resulting in the development of a new aircraft based high-energy triple-pulsed 2- $\mu \mathrm{m}$ IPDA lidar. This IPDA promises a new avenue for remote sensing from space [4]. The 2- $\mu \mathrm{m}$ triplepulse laser transmitter is the key component for this system. The performance of this transmitter is critical for achieving measurement sensitivity, accuracy, and range. The unique feature of this laser is the production of triple Q-switched pulses, separated by $150-200 \mu \mathrm{s}$, using a single pump pulse. The laser was developed at NASA LaRC and is based on Ho:Tm:YLF crystal technology [3]. Among other components, LaRC has been developing new technologies for the $2-\mu \mathrm{m}$ lasers which include timing control, seeding, locking, and narrowing frequencies for both wind and $\mathrm{CO}_{2}$ measurements [4]. Advanced wavelength control of the current triple-pulse laser uses a single seed laser and provides any offset-locked frequency within $32 \mathrm{GHz}$ with respect to the $\mathrm{CO}_{2} \mathrm{R} 30$ line center $\left(\lambda_{\mathrm{C}}\right)$ shown in figure 1 . The direct-detection IPDA receiver is based on the state-of-the-art, very low noise, $4 \times 4$ pixels MCT e-APD array [5]. This e-APD detection system has been developed and tested at GSFC for 1.6- $\mu \mathrm{m}$ pulsed IPDA lidar for different atmospheric trace gases such as $\mathrm{CO}_{2}$ and $\mathrm{CH}_{4}$. The projected 2- $\mu \mathrm{m}$ IPDA lidar parameters for the space-based system, and environmental parameters are listed in Table 1.

Table 1 2- $\mu$ m triple-pulse IPDA lidar Parameters.

\begin{tabular}{|l|l|}
\hline \multicolumn{2}{|c|}{ IPDA Lidar Transmitter } \\
\hline On-line wavelength & Tunable \\
\hline Off-line wavelength & $2051.1915 \mathrm{~nm}$ \\
\hline Pulse energy & $50 / 15 / 5 \mathrm{~mJ}$ \\
\hline Pulse width & $30 / 60 / 100 \mathrm{~ns}$ \\
\hline Pulse separation & $150-300 \mu \mathrm{s}$ \\
\hline Pulses repetition rate & $50 \mathrm{~Hz}$ \\
\hline Beam divergence & $100 \mu \mathrm{rad}$ \\
\hline Laser line-width & Transform Limited \\
\hline Frequency control accuracy & $650 \mathrm{kHz}$ \\
\hline Wall-plug efficiency & $2 \%$ \\
\hline Beam expansion & $\times 10$ \\
\hline \multicolumn{2}{|c|}{ IPDA Lidar Receiver } \\
\hline Optical efficiency & $60 \%$ \\
\hline Telescope diameter & $1.5 \mathrm{~m}$ \\
\hline Optical filter spectral width & $1 \mathrm{~nm}$ \\
\hline Field-of-view & $150 \mu \mathrm{rad}$ \\
\hline Detection system NEP & $1 \mathrm{fW} / \mathrm{Hz}$ \\
\hline Detector responsivity & $295.3 \mathrm{~A} / \mathrm{W}$ \\
\hline Detector gain & 308 \\
\hline Detector excess noise factor & 1.03 \\
\hline Detection bandwidth & $10 \mathrm{MHz}$ \\
\hline Laser-to-telescope overlap & 1.00 \\
\hline \multicolumn{2}{|c|}{ Settings and Environment } \\
\hline Background solar irradiance & $0.5 \mathrm{~mW} / \mathrm{m}^{2} \cdot \mathrm{nm} \cdot \mathrm{sr}$ \\
\hline Atmospheric model & $\mathrm{US} \mathrm{Standard}$ \\
\hline Surface reflectivity & 0.51 \\
\hline Aerosols optical depth & 0.0165 \\
\hline Platform altitude & $400 \mathrm{~km}$ \\
\hline Platform speed & $28,000 \mathrm{~km} / \mathrm{hr}$ \\
\hline Integration time & $10 \mathrm{~s}$ \\
\hline
\end{tabular}

* RRV surface reflectivity including the $24 \%$ lidar enhancement factor.

\# Tunable within $2050.97 \mathrm{~nm}$ to $2051.19 \mathrm{~nm}$, as indicated by the shaded area of Figure 1. 


\section{IPDA RETURN POWER}

The IPDA performance was estimated using the approach presented by Refaat et al. [3]. IPDA return signal power, total noise equivalent power (NEP) and signal-to-noise ratio (SNR) are shown in figure 3 as a function of on-line wavelength. The highest pair of transmitted energies (50 and $15 \mathrm{~mJ}$ ) are assigned to on-line to account for the absorption loss in the measurement column. Off-line transmitted energies are set to either 15 or $5 \mathrm{~mJ}$, which result in 185.55 or $37.11 \mathrm{nW}$ return power, and 0.81 or $0.37 \mathrm{nW}$ total NEP, respectively. Corresponding off-line SNR are 229 and 101. Online wavelength selection close to R30 line center results in lower return power with total noise dominated by fixed background and electronic noise. Away from line center, on-line return power increases with shot-noise dominating total NEP and resulting in enhanced SNR. High energy and low detection noise combination allow short-time measurement over low reflectivity regions such as snow covered regions and ocean surface.

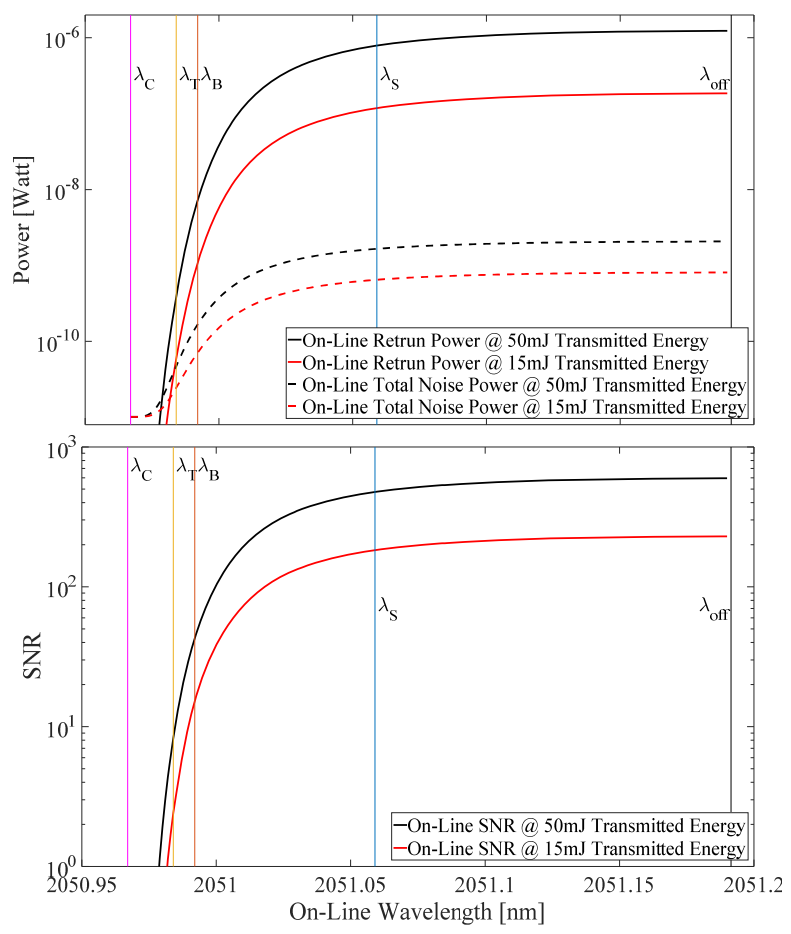

Figure 3 On-line surface return power detected by the IPDA form space and the corresponding integrated noise equivalent power using 50 and $15 \mathrm{~mJ}$ transmitted energies variation with on-line wavelength (top).

Return power and noise are used to estimate SNR variations with on-line wavelength (bottom).

\section{SENSITIVITY ANALYSIS AND ERROR}

Analysis of both random error associated with IPDA, and systematic errors from atmospheric and instrument biases were estimated. Residual systematic errors in $\mathrm{CO}_{2}$ measurement arise due to uncertainties in the knowledge of atmospheric and the IPDA instrument capabilities are shown in figure 4 with legend list in Table 2 . The estimated $\mathrm{CO}_{2}$ differential optical depth error from atmospheric effects include uncertainties in temperature $\left(0.5^{\circ} \mathrm{C}\right)$, pressure $(100 \mathrm{~Pa})$, relative humidity $(10 \%)$ and $\mathrm{H}_{2} \mathrm{O}$ interference. A normally distributed random number generator was used to simulate the variability of these fields to evaluate the systematic error. $\mathrm{CO}_{2}$ differential optical depth bias errors resulting from the IPDA transmitter uncertainties including on- and off-line laser position jitters $(650 \mathrm{kHz})$ and laser spectral profiles were also estimated.

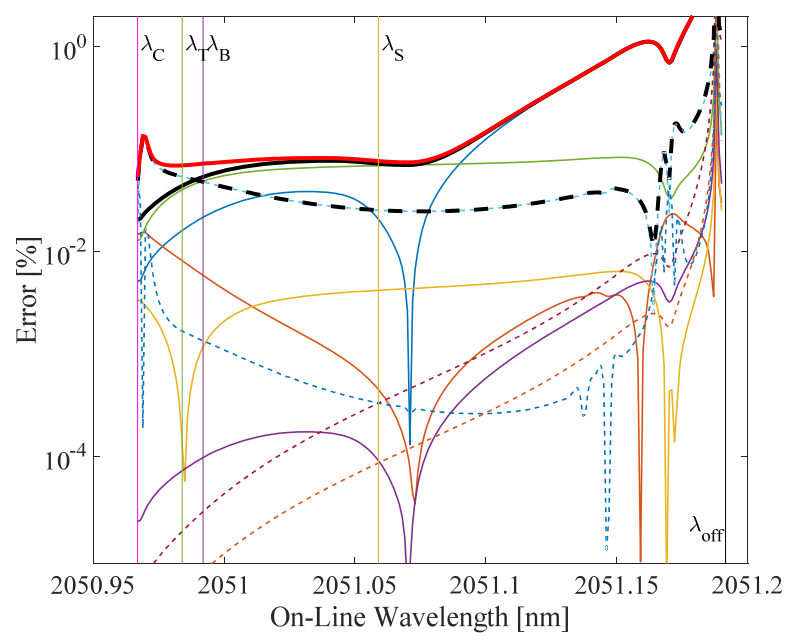

Figure 4 Atmospheric and laser transmitter errors and total systematic error estimation versus on-line wavelength for $\mathrm{CO}_{2}$ measurement using the 2- $\mu \mathrm{m} \mathrm{IPDA}$ lidar. Figure legend is in Table 2.

Table 2 Legends of figure 4.

\begin{tabular}{|c|c|}
\hline $\begin{array}{l} \\
\\
\\
\end{array}$ & $\begin{array}{l}\mathrm{H}_{2} \mathrm{O} \text { Interference Error } \\
\text { Temperature Error } \\
\text { Pressure Error } \\
\text { Relative Humidity Error } \\
\text { Range Error } \\
\text { Total Atmospheric Errors } \\
\text { On-Line Jitter Error } \\
\text { Off-Line Jitter Error } \\
\text { On-Line Width Error } \\
\text { Off-Line Width Error } \\
\text { Total Transmitter Erros } \\
\text { Total Systematic Erros }\end{array}$ \\
\hline
\end{tabular}


Random errors for the combination of 50, 15 , and $5 \mathrm{~mJ}$ on- and off-line energies and total (random + systematic) errors are shown in figure 5 with legend list in Table 3. Measurements with two weighting functions, at $50 \mathrm{~Hz}$ each, with the triple pulse system can be accomplished using two onlines and a common off-line. The near optimum random error for each pair is $<0.12 \%(<0.5 \mathrm{ppm})$, and the residual systematic error is $<0.07 \%(0.3$ $\mathrm{ppm})$. Measurements can be optimized by tuning on-lines based upon ground target scenarios, environment and science objectives. With $10 \mathrm{MHz}$ detection bandwidth, surface ranging with an uncertainty of $<3 \mathrm{~m}$ can be achieved as demonstrated from earlier airborne flights [6].

\section{CONCLUSIONS}

High-energy triple-pulse 2- $\mu$ IPDA technology developments at LaRC are in progress to enable $\mathrm{CO}_{2}$ column measurements from space. Currently

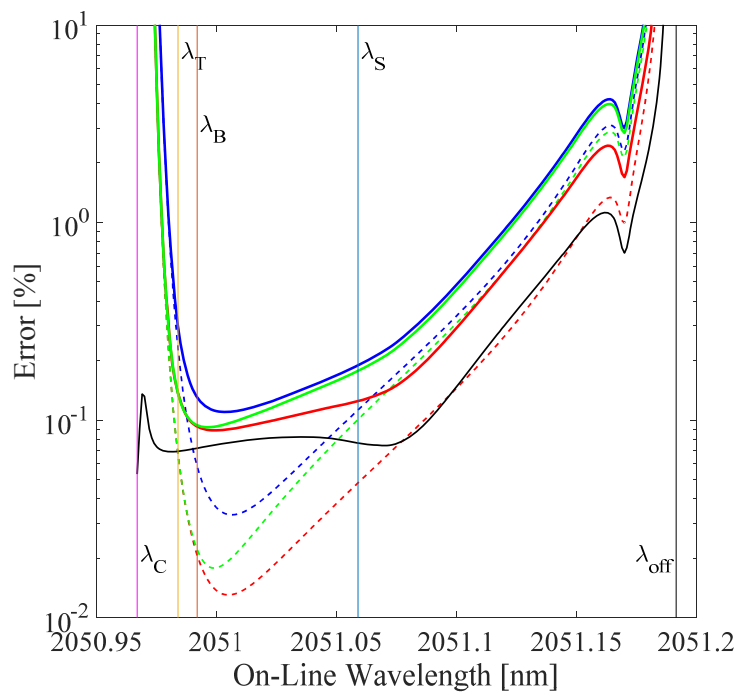

Figure 5 Random errors variation with on-line wavelength obtained using different on and off-line transmitted energy combinations. Total error for $\mathrm{CO}_{2}$ measurement using the 2- $\mu$ IPDA lidar is obtained by adding random and total systematic errors. Figure legend is in Table 3.

Table 3 Legends of figure 5.

\begin{tabular}{|ll|}
\hline$\cdots$ & Random Error, $E_{\text {on }}=50 \mathrm{~mJ} \& \mathrm{E}_{\text {off }}=15 \mathrm{~mJ}$ \\
\hline & Random Error, $\mathrm{E}_{\text {on }}=15 \mathrm{~mJ} \& \mathrm{E}_{\text {off }}=5 \mathrm{~mJ}$ \\
\hdashline & Total Systematic Error \\
\hline & Total Error, $\mathrm{E}_{\text {on }}=50 \mathrm{~mJ} \& \mathrm{E}_{\text {off }}=15 \mathrm{~mJ}$ \\
& Total Error, $\mathrm{E}_{\text {on }}=15 \mathrm{~mJ} \& \mathrm{E}_{\text {off }}=5 \mathrm{~mJ}$ \\
& Total Error, $\mathrm{E}_{\text {on }}=50 \mathrm{~mJ} \& \mathrm{E}_{\text {off }}=5 \mathrm{~mJ}$ \\
\hline
\end{tabular}

IPDA development is focused on measuring both $\mathrm{H}_{2} \mathrm{O}$ and $\mathrm{CO}_{2}$ simultaneously and independently. This allows measurement adaptability over a variety of atmospheric and target conditions. An airborne 2- $\mu \mathrm{m}$ IPDA lidar has demonstrated $\mathrm{CO}_{2}$ measurements over land and ocean. Projected capability of high pulse energy $2-\mu \mathrm{m}$ laser and an MCT e-APD detection system were incorporated for modeling the performance of a space-based IPDA. Random and systematic errors from the instrument and atmospheric effects including influences of $\mathrm{H}_{2} \mathrm{O}$ were evaluated. The projected performance shows that high precision $(0.5 \mathrm{ppm})$ and low bias $(0.3 \mathrm{ppm})$ low tropospheric weighted dry-air column $\mathrm{CO}_{2}$ mixing ratio measurements can be made from space with total error of $<0.8$ ppm for standard atmospheric condition and RRV reference with 10 second averaging.

\section{ACKNOWLEDGEMENTS}

This work was funded and supported by NASA Earth Science Technology Office.

\section{References}

[1] National Research Council, 2007: Earth Science and Application from Space, National Imperatives for the Next Decade and Beyond.

[2] European Space Agency Report for Assessment, 2008: A-SCOPE advanced space carbon and climate observation of planet Earth, SP-1313/1.

[3] T. Refaat, U. Singh, J. Yu, M. Petros, S. Ismail, M. Kavaya, K. Davis, 2015: Evaluation of an airborne triple-pulsed $2 \mu \mathrm{m}$ IPDA lidar for simultaneous and independent atmospheric water vapor and carbon dioxide measurements, Appl. Opt. 54, 1387-1398.

[4] U. Singh, B. Walsh, J. Yu, M. Petros, M. Kavaya, T. Refaat, N. Barnes, 2015: Twenty years of Tm:Ho:YLF and LuLiF laser development for global wind and carbon dioxide active remote sensing, Opt. Mater. Exp. 5, 827-837.

[5] X. Sun, J. Abshire, J. Beck, 2014: HgCdTe e-APD detector arrays with single photon sensitivity for space lidar applications, Proc. of SPIE 9114, 91140K.

[6] T. Refaat, U. Singh, J. Yu, M. Petros, R. Remus, S. Ismail, 2015: Double-pulse 2- $\mu \mathrm{m}$ integrated path differential absorption lidar airborne validation for atmospheric carbon dioxide measurement, Appl. Opt. 55, 4232-4246. 